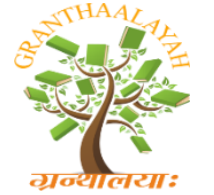

INTERNATIONAL JOURNAL OF RESEARCH GRANTHAALAYAH A knowledge Repository

RAST - 17

\title{
COMPARATIVE STUDY ON FEED FORMULATION SOFTWARE- A SHORT REVIEW
}

\author{
Vishal Patil $^{* 1}$, Radha Gupta ${ }^{2}$, Rajendran $D^{3}$, Ravinder Singh Kuntal ${ }^{1}$ \\ ${ }^{* 1}$ Assistant Professor, Research Scholars, Department of Mathematics, Jain University, \\ Bangalore, Karnataka, India \\ ${ }^{2}$ Professor, Department of Mathematics, Dayananda Sagar College of Engineering, Bangalore, \\ Karnataka, India, \\ ${ }^{3}$ Sr. Scientist, NIANP (National Institute of Animal Nutrient and psychologist), Adugodi, \\ Bangalore, Karnataka, India
}

DOI: https://doi.org/10.29121/granthaalayah.v5.i4RAST.2017.3311

\begin{abstract}
The paper highlights the different feed formulation software's for least cost formulation of livestock and animals, where the comparison of techniques is done based on different aspects like data collection, software used, price, scope and limitations. Feed formulation requires large amount of data about the composition of feeds, environment conditions, and availability of feeds. Development of Software's for feed formulations is changing with change in computer. With advancement of technology, the feed formulation can be calculated for ' $n$ ' number of feed stuff but still Linear Programming is used as base for mathematical modelling, where uses of nonlinear programming is very less. Maximum number of feed formulation software's is developed to select the feeds for formulation within budget of the farmers or dairy industry.
\end{abstract}

Keywords: Feed Formulation Software; Linear Programming; Mathematical Modelling; Livestock and Animal.

Cite This Article: Vishal Patil, Radha Gupta, Rajendran D, and Ravinder Singh Kuntal. (2017). "COMPARATIVE STUDY ON FEED FORMULATION SOFTWARE- A SHORT REVIEW." International Journal of Research - Granthaalayah, 5(4) RAST, 105-115. https://doi.org/10.29121/granthaalayah.v5.i4RAST.2017.3311.

\section{Introduction}

Livestock plays an important role in the Indian economy. Livestock sector recorded growth in value of output about $4.8 \%$ per annum. The eleventh five year plan expected higher growth in twelfth five year plan. The increased demand for protein foods in the country is the main driver for growth, which also includes small stakeholders and landless farmers, account for major share 
in ownership of livestock which has recorded 5\%growth per annum previously, can grow up to 6\% per annum.(Annual Report 2015-2016)

Feed formulation is one of the important aspects of animal feed industry. Balancing the feed stuffs is big challenge faced by the industries when the costumers and requirement increases. Development of animal feed industry depends upon the quality of feed and quality of feed is based upon the raw material used to formulate feed(ration). Ration is the total amount of feed given to the animal on a daily basis while, ration formulation can be defined as the process by which different ingredients are combined in a proportion necessary to provide the animal with proper amount of nutrients needed at a particular stage of production,(Afolayan and Afolayan 2008).

The first ever computer used for feed formulation was made in 1951 when F.V. Waugh published a paper titled "The Minimum-Cost Dairy Feed". Dent \& Casey (1967) authored the first published book on computer-based formulation entitled as "Linear Programming and Animal Nutrition." Computers used by feed industry for practical feed formulation started in the year 1970s when computers were affordable for large industries. Later, use of computers increased for feed formulation in the 1980s when personal computers became commercially available (A. Victor Suresh, 2016). In the present age, feed formulation without the use of computers is very rare. This paper gives the comparison of 6 different feed formulation software's based on specific inputs. With the increase in capabilities of computers, the calculation time of feed formulation can be minimized.

There are many conventional and non-conventional methods of feed formulation. Conventional methods are: Simultaneous equation method, trial-and-error method, two by two matrix method and square method. After this, new methods like linear programming, stochastic programming, goal programming, least-cost formulation and non-linear programming came into effect (Pratiksha Saxena 2010). Selecting appropriate method depends upon the objective for which feed is formulated for example, minimising the cost or maximizing milk yield.

For feed formulation, various feed standard tables should be considered for different livestock. It was found that there are different categories of livestock. In case of cattle or buffalo, it is categorized in three ways: Dry animals with pregnancy; Animals in milk and Milk animal with pregnancy. Similarly, other poultry and livestock animals are categorised. Depending upon the category of the animal, age and weight, the requirement of nutrients vary. One of the major problems while formulating any mathematical model or linear model is dealing with constraints. Slight variation in the constraint makes a lot of difference in the cost of the feedstuff. Therefore, finding correct values of constraints are very important, which can be easily done by using nutrient requirement software's developed by single click (Vishal Patil et. al., 2017).The major challenge faced by animal feed industry is the shortage of feed and fodder, breed improvement, animal disease, skill and quality service to the farmer in order to improve the productivity.

\section{Feed Formulation Software}

There are various software which are developed for feed formulation of cattle, buffalo, pig, poultry etc. Some of these are discussed below. 


\subsection{Kasturi Feed Formulation}

FEED FORMULATION (www.kasturi.info/ feed.htm) is simple and practical feed formulation software, is developed by K. Chandra Shekhar in the year 2002. Itis meant for least cost feed formulation with user friendly interface. A person with basic knowledge can easily use this software. It comes with two functions, Optimize: where it uses liner programming to optimize feed formulation at least cost and Analyse: If we don't want least cost formulation but only want to know the nutrient values, this will calculate the Nutrients Values and the Formula Cost on entering the ingredients quantity and rate. It is suitable for Egg Producers, Broilers, Nutritionist, Hatcheries, Feed Manufacturers, etc.

This software can easily be downloaded from the internet free of cost and without a validity period. It comes with a user manual by which the two functions can be performed without any confusion. Once it is opened, the main menu appears which contains

- Animal Types - (Layers, Broilers, Sheep, Pigs, Fish, etc., )

- Feed Types - Mentioning the feed types (Chick, Grower, Layer1, Layer2, Layer3 for Layers)

- Ingredients-Mentioning name of the ingredients and the price

- Nutrients - Mentioning the Nutrient Names and their Units.( Energy, Protein, Fat, Fiber, Lysine, etc.,)

- Nutritional Composition - Mentioning the Nutrient Values for each Ingredient

- Ingredients Selector - Select Ingredients which are used for a particular animal type

- Nutrients Selector - Select Nutrients which are to be calculated for a particular animal type

- Formula Analysis - New Feed Formulation is followed as

Step 1: Select the Animal Type

Step 2: Select the Feed Type.

Step 3: Select the Date on which you are formulating.

Step 4: Select Task Optimize or Analyse

Step 5: Select the weight of the feed formula.

Step 6: Next, if you want mention any comments you can do so in the Remarks field.

In this software, provision is given to set minimum/maximum quantity of ingredient, and fixing the rate of ingredient. One can add new ingredient by clicking on add button. And in case the solution is not found then user can change the bounds and optimize it again. In this software, there is an option for saving as well as taking print of least cost formulation.

Kasturi feed formulation is compatible with Windows XP with SP2 / Windows 2000 with SP4 / Windows Server 2003 with SP1 / Windows Vista.Software developedis based on Microsoft.NET Platform and its only requirement is that Microsoft's.net 2.0 should be present in the system on which this is going to be used as in [7] 


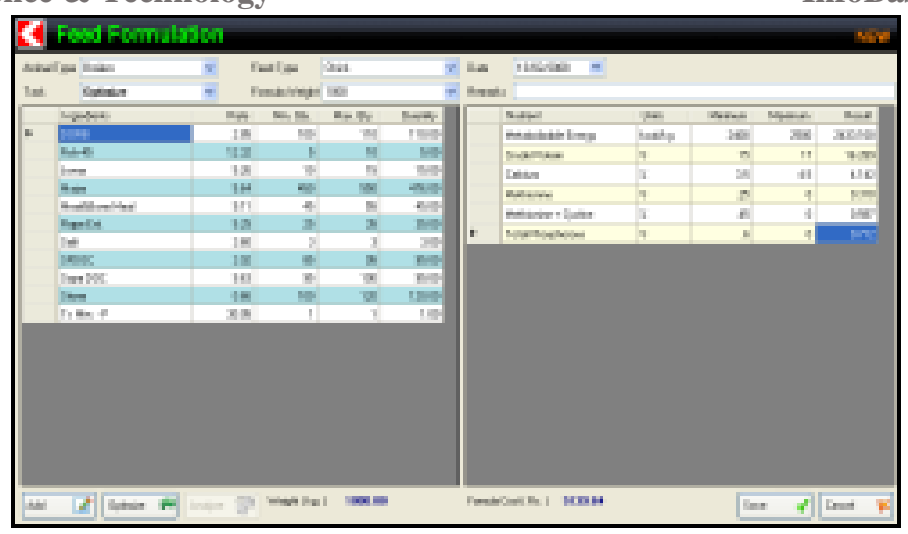

Screen shot of feed formulation software

\subsection{Winfeed 2.8 Software}

WIN FEED (www.winfeed.com) is the cheapest least cost feed formulation software developed in the year 2012. It is equally useful for ruminants and non-ruminants such as poultry, cattle, sheep, horses, dogs, cats, fish and aqua culture etc. WinFeed works in two modes, Linear Mode: suitable for conventional feed formulation and Stochastic Mode: specifically for probability based least cost feed formulation.

By providing minimum personal information, the user can download and install the demo version of the software with the installation key. The user can also download feed store files and nutrient requirement files. It allows to save the animal's nutrient requirement in one file and the feed store (Ingredient Composition Database) in another file. Once the user selects the feed store, a main window appears where ingredients are selected. Nutrient requirements, their price and nutrient composition are entered manually in the main window. WinFeed is connected with MS Excel where data can be Imported or Exported between Excel and Winfeed. The method of formulation can be selected as Linear or Stochastic. After fixing the minimum and maximum limits for nutrients, the ingredient formula is saved and its nutrient analysis is saved in a text file. This text file can be opened in Microsoft Word or Microsoft Excel for further processing. Formula reports can be prepared in graphical form using pie chart and bar chart. It also allows the user to print out the feed formula.

WinFeed is compatible with Windows NT, 98, Me, 2000, XP and Windows 2003. Unix/Linux compatible versions are also available on request. It is the first feed formulation software in the world that is capable of doing Stochastic Formulation and it gives up to $99.99 \%$ assurance of meeting nutrient requirements in the feed. However, it doesn't display the unit cost of each ingredient. The formulate button is also not easy to find. The user has to click the Formulate button on top of the menu or press Ctrl+F to get the result (Wan Nurhayati et al., 2015). Only the demo version is free for download which cannot handle more than 20 Ingredients and 20 Nutrients and, it does not support hard copy printing or data exporting functions. The full version costs only $£ 100$ as in [8]. 


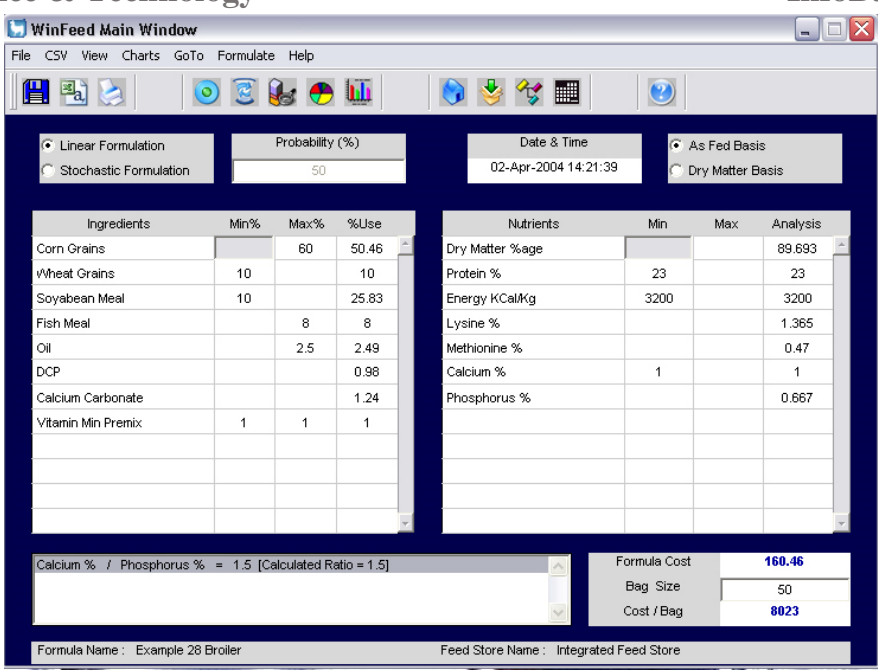

Screen shot of win feed 2.8 software

\subsection{AFSO (Animal Feed Optimization Software)}

AFOS (www.animalfeedsoftware.com) is built using hybrid-cloud technology which allows system installation on cloud or on the user's PC as a standalone application and from mobile devices using just a browser. The standalone application is focused on users who want a traditional application with database saved locally. It is mainly developed for Nutritionist Professional, Feed Production Professionals; Farming Professionals which helps the user develop, manage, store, analyse, collaborate and exchange animal feed formulas. It is available in English, French, Italian, etc.

AFOS supports multi-plant and multi-animal group data with no limitations on number of nutritional instances including plants, animal groups, nutrients, ingredients, products and recipes. The user can freely add, edit, remove and customize all data, including adding new currencies, editing nutrient units, weight units, prices and additional costs. For a complex process, AFOS allows creation of templates to reduce time for repetitive actions. User experience is additionally improved by smart filters and advanced search as in [11]. AFOS allows printing and exporting of multiple formulas to all major formats (word, pdf, excel and csv)

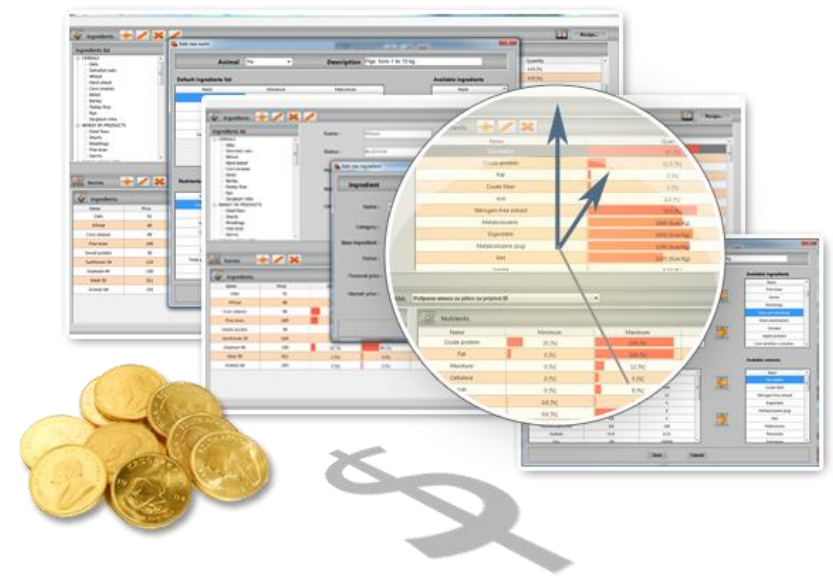

Screen shot of feed AFSO software. 


\subsection{FEED ASSIST (An Expert System on Balanced Feeding for Dairy Animals)}

"Feed Assist" is a farmer friendly expert system for balancing the feed formulation of dairy animals. It has been developed using linear programming. "Feed Assist" does not require much expertise to operate and enables the farmers to formulate least cost rations for different categories of livestock using locally available feed resources. It has huge data according to (ICAR, 2013a) standards. The expert system provides a powerful tool to the farmers in resolving the complexities involved in ration formulations.

The system is developed using Visual Basic in connection with MS-Access in the back end. It is integrated as a mobile app owing to the wider use of mobile when compared to the personal computer. Once it is opened, the main menu appears as shown in screen shot where the user has to select the Language (English, Hindi, Kannada), type of animal (cattle or buffalo) and then provide information about the same like body weight, average daily growth, average milk yield. Nextstep is to select the available feed then one click on FORMULATION button solution will display as Final Result form. The Final Result form screen shot shows the cost of ration, and nutrients, total amount of ration to be feed as in[12].
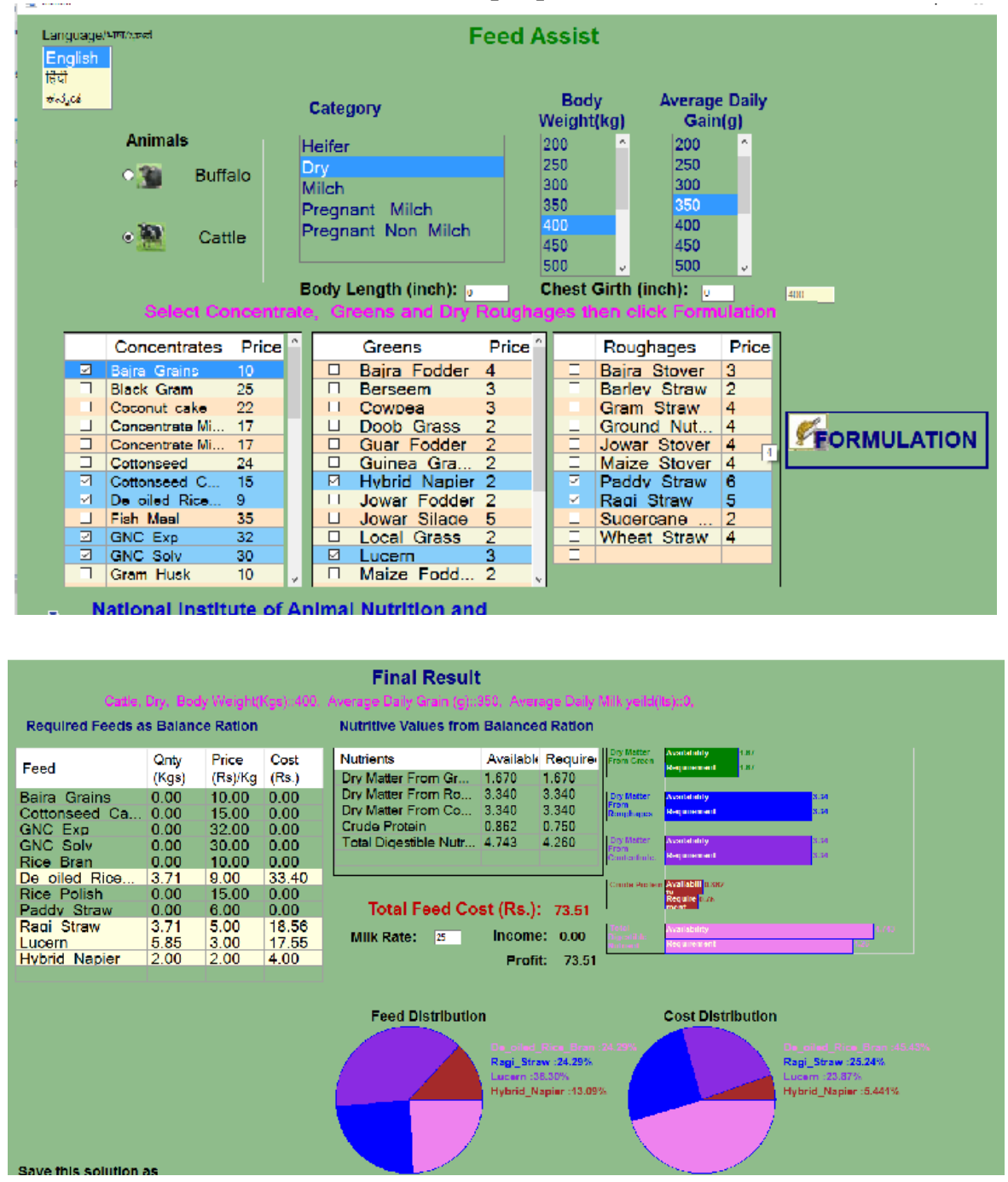

Screen shot of feed Assist system 


\subsection{Feed-Mixer}

Feed-Mixer is a web application which is developed to help the farmers to calculate the least possible cost of feed formulation by comparing the ingredient price between suppliers. Besides, the Feed-Mixer is able to help farmers utilize the budget by calculating the maximum amount of feedsthat can be produced within the budget and maximum number of feeding days of the animals. In conclusion, the Feed Mixer is able to help farmers lower the production cost and at the same time maintain a good livestock production.

\section{Benefits of Feed Mixer}

- Reduce production cost in animal farming

- Utilize budget for feed formulation

- Provide suggestion for ingredient replacement: It gives suggestion for replacement if any of the particular ingredient if it is not in stock for feed formulation.

- Provide ingredient information: It gives information about nutritional composition and to educate the users in preparing the feed formula.

- Provide supplier information: Feed Mixer not only gives which supplier is selling the ingredient at cheaper price, but also provides the information of each supplier such as contact number, email and address location.

- Generate report: It provides report generation feature for feed formulation, budget analysis, formula details, formula list, ingredient list and nutrient list for record keeping purpose.

- Feed Mixer free trial is available for public users to use the system without having to pay any subscription feesas in [6]

\subsection{Eco-Mix}

Eco-Mix is (www.logicsoftsolutions.com) user friendly windows-based software which prepares any kind of balanced feed with least cost. It is developed by LOGIC SOFT SOLUTIONS, established in the year 1998. This software can be used for poultry, cattle, horse, fish, pets, ruminants and non-ruminants etc.

Requirements for standard rations are available as default and formulas can be compared with standard feed types. Modifications like add, delete, rename Ingredients and Nutrients, and change minimum and maximum values of Ingredients and Nutrients, Change specifications for standard rations, nutrient values of feed ingredients can be performed very easily. While preparing the formulation after providing all the inputs required if it shows 'solution is not found' then it will indicate which nutrient is out of range and advise, how to modify the formula. The user can take the print. This software is already provided to Hatcheries, Poultry Farms and Feed Manufacturers (Poultry, Cattle \& Live Stock), Consultants, Doctors, Veterinary Colleges, Pharmaceutical Companies. Only the demo version is free for download which is a Web based version as in [9] 


\subsection{FeedMU2}

FeedMU2 is the new version of FeedMU (http://feedmu.codeplex.com) last edited in 2009. FeedMU (pronounce feed-mew) is a simple feed formulation program based upon Trials and Errors method and Linear Programming (simplex method) for least cost feed formula. It can be used for feed formulation as simple feed in animal farms and complex feed in feed mill. This software is created for nutritionists, veterinarians, feed formulators, feed manufacturers and others involved in formulating diet for animals.

FeedMU is a Windows-based application developed using Visual basic, a full-featured .NET application for feed formulation. It is easy to install and is equipped with a software save formula classified by farmer's name (or customers) and Export formula report to PDF format. It can manage animal requirements, ingredients details, and ingredients composition for formulating a well-balanced diet. FeedMU2 is developed using .NET framework 2.0 technologies. This is available in two languages English and Thai. It Open multi-formula (Tabbed User Interface) and shows old cost, current cost, old weight, and current weight for comparison. User can perform modifications like add and delete directly into grid as in [10].

\section{Other available packages (in random order):}

- FeedSoft - www.feedsoft.com( Stopped services from Nov 1 2016)

- Feed Management Systems - www.feedsys.com

- Creative Formulation Concepts - www.agri-data.com

- Global Mix - www.formatinternational.com

- WinPas - www.winpas.com

- Alfablend - www.fnt.be

- Feedmania - http://saltbush.une.edu.au

- precision FEEDING - www.dinamicagenerale.com

- Maximix - www.ndcontrols.com

- AutoFeed - www.feedlab.eu

- Bestmix-www.bestmix.com

- UFFDA-http://www.poultry.uga.edu/poultrysoftware.htm

- PoultryHub, Feed Formulation, Poultry CRC, copyrighted 2006-2015. http://www.poultryhub.org/nutrition/feedformulation/

\section{Analysis}

All the feed industries expect feed formulation to meet the specific requirements of animals like maintenance, growth, reproduction and production, and profit of the industry.

There are different types of feed stuff used by feed industries:

- Roughages: It is a plant-based feed stuff with higher fibre content forages and provides a range of nutrients to the animal. Roughages can be fed on dry matter basis or fresh basis, different types of roughages are paddy straw, Co-4 grass, Maize Fodder, Ragi straw, Berseem, Wheat straw, Maize Stover etc.

- Concentrate: It is a feed in which high amount of nutrients are concentrated in a small amount of dry feed such as Maize, soya DOC, Copra DOC, Cotton DOC, Cotton seed etc. 
- Minerals and other sources: These are essential for functioning of a body. Minerals always need to be included in the formulation of feed in order to meet the requirements. Salt, sodium, potassium together with chloride are the important micro minerals.

\section{Feed formulation software based on linear programming:}

Linear programming is a method of developing a mathematical model to achieve least cost or maximize profit as the objective. Constraints are the feeds and nutrient requirement that are defined as minimum and maximum level. Cost optimization is achieved only when the developer has a knowledge of how to define and manage constraints correctly.

\section{Feed Formulation based on Stochastic Programming:}

Stochastic programming is non-linear optimization programme to manage risk in the ingredient variability and meeting nutrient requirements of the animal. It is not used widely but has the potential to provide the most cost effective formula as in [13]

\section{All feed formulation software must have the following database:}

- Ingredient: Database of feed ingredient and cost is very important. Availability of feed and nutrient composition like percentage of dry matter, protein, energy, calcium, phosphorus present in the feed etc., plays vital role in feed formulation.

- Nutrient: Nutrients are the key factor for the feed formulation. Database of nutrient may be simple with corresponding unit. Different category of animal has different requirement of nutrient and restriction on nutrient.

- Nutrient specification: It defines the nutrient level required in the formula and feed ingredient inclusion level. The limits are said to be constraints which have to be satisfied in formulation.

- All the software which is mentioned above aimed to provide balanced nutrients or ration for livestock or animals at least cost, either by linear programming or stochastic method.

- Overview of formulation process is given in the following chart.

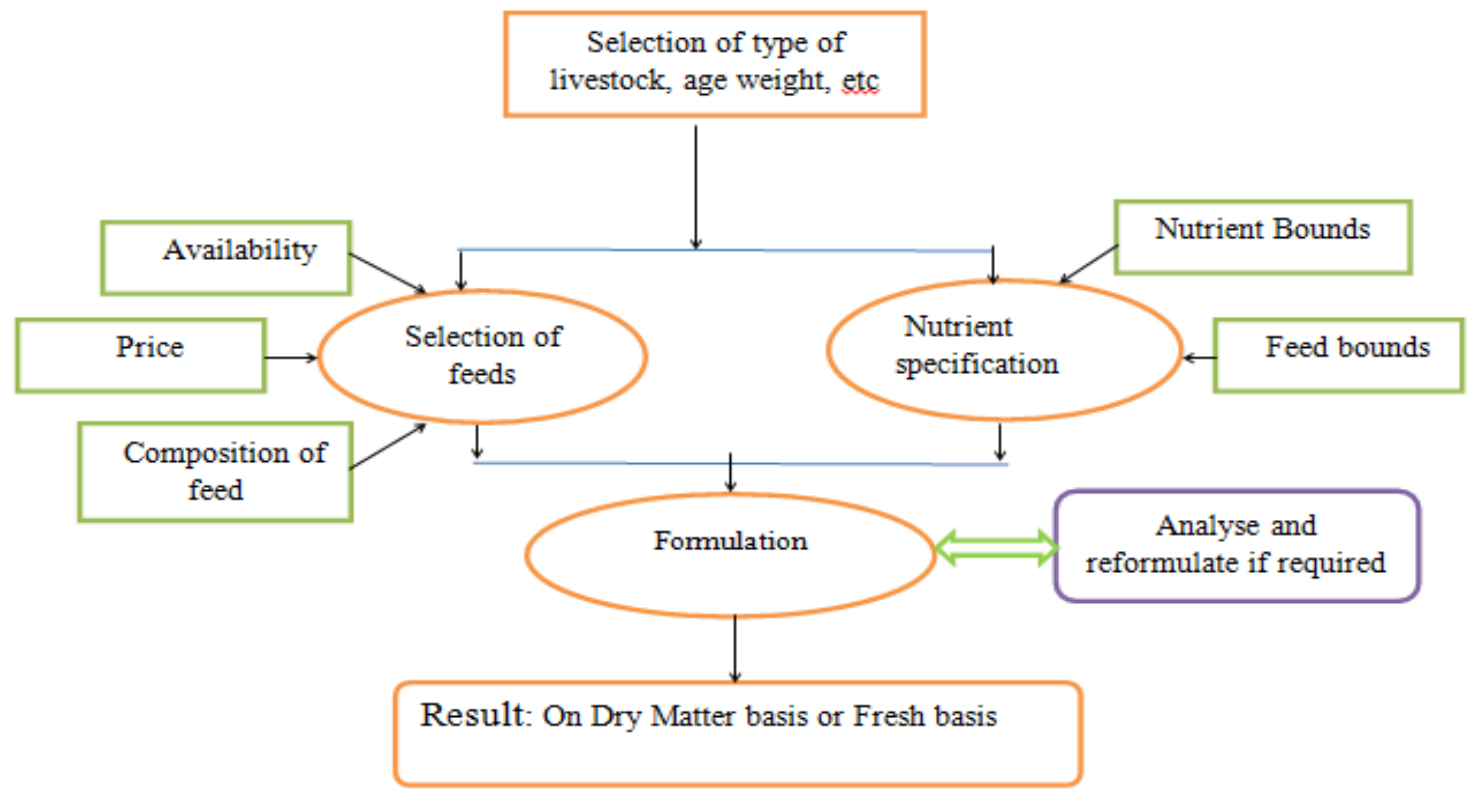




\section{Conclusion}

In the year 1967, the first computer-based formulation book was published. In 1970, feed industries started using computers for practical feed formulation. In 1980s, computerized linear program was developed for least cost feed formulation. In the present age, a number of software and mathematical models are developed for finding least cost and maximizing the profit. In our study, when we talk about the cost, many software (WinFeed2.8, FeedMU2, Eco-MIX, AFSO, Feed-Mixer etc) are not free and only trial versions are available but they have student offers, where "Feed Formulation" and "Feed Assist" are free and easily downloaded by giving minimum information.WinFeed2.8 is the only software which uses Stochastic method in feed formulation and gives the $99 \%$ assurance of meeting the nutrient requirement. Software which use linear programming are FeedMU2, Eco-MIX, AFSO, Feed-Mixer, WinFeed. Win Feed is the only software which formulates the feed by both the methods. Many feed formulation software have some specific requirement of hardware and platform without which, the user cannot run them. The introduction of cloud computing has increased the use of feed formulation where, the user buy a service and can connect through internet and access the database stored in the cloud and perform formulation. Feed formulation software is easy to use, saves time and minimizes the human error of calculation. This study give researchers a motivation to work on some more efficient feed formulation software's which can deal not only with linear formulation but with non-linear as well as multi objective feed formulations.

\section{References}

[1] Annual Report 2015-16, Department of Animal Husbandry, Dairying and Fisheries, Ministry of Agriculture and Farmers Welfare, Govt. of India.

[2] Afolayan, Matthew Olatunde and Moji,2008, "NIGERIA ORIENTED POULTRY FEED FORMULATION SOFTWARE REQUIREMENTS" Journal of Applied Sciences Research', 4(11): 1596-1602

[3] Pratiksha Saxena, 2010, "FEED FORMULATION SOFTWARE: A COMPARATIVE STUDY" publication at: https://www.researchgate.net/doi: 10.1079/PAVSNNR20116057

[4] Vishal Patil, Radha Gupta , Rajendran D ,Ravinder Singh Kuntal, 2017, "DESIGN AND VALIDATION OF RATION FORMULATION OF CATTLE - A RESEARCH INVESTIGATION" International Journal of control theory and systems, Volume 9 • Number 42, ISSN : 0974-5572

[5] A. Victor Suresh , 2016 , "FEED FORMULATION SOFTWARE", Chapter 2 in Aqua feed Formulation, Academic Press, Pages 21-32

[6] Wan Nurhayati Wan Ab. Rahman, and LokeMeeSie, 2015, "FEEDMIXER WEB APPLICATION FOR ANIMAL FEED FORMULATION" Recent Advances on Computer Engineering, ISBN: 978-1-61804-336-8

[7] Feed Formulation. (2008). Retrieved from http://kasturi.info/feed.htm

[8] WinFeed 2.8. (2012). Retrieved from http://www.winfeed.com/download/demo.shtm

[9] Eco-Mix. (1998-2005) www.logicsoftsolutions.com

[10] FeedMU2. (2009),http://feedmu.codeplex.com

[11] AFOS. www.animalfeedsoftware.com

[12] U. B. Angadi1, S. Anandan2, N. K. S. Gowda2, D. Rajendran2, L. Devi2, A.V. Elangovan2 and S. Jash2, 2016, "FEED ASSIST- AN EXPERT SYSTEM ON BALANCED FEEDING FOR DAIRY ANIMALS" Agris on-line Papers in Economics and Informatics Vol. 8, No. 3, pp. 3 - 12. ISSN 1804-1930, DOI 10.7160/aol.2016.080301. 
[Patil et. al., Vol.5 (Iss.4: RAST), April, 2017]

ICV (Index Copernicus Value) 2015: 71.21

Recent Advances in Science \& Technology
ISSN- 2350-0530(O), ISSN- 2394-3629(P) IF: 4.321 (CosmosImpactFactor), 2.532 (I2OR) InfoBase Index IBI Factor 3.86

[13] I.U Udo, C.B. Ndome and P.E. Asuquo, 2011, USE OF STOCHASTIC PROGRAMMING IN LEAST-COST FEED FORMULATION FOR AFRICAN CATFISH (CLARIAS GARIEPINUS) IN SEMI-INTENSIVE CULTURE SYSTEM IN NIGERIA, in 'Journal of Fisheries and Aquatic Sciences',6:447-455

\footnotetext{
*Corresponding author.

E-mail address: vishal.patil33@rediffmail.com
} 